folk/ed. Derg, 2020; 26(2):281-296

DOI: $10.22559 /$ folklor.1207

\title{
İşlevselcilik Açısından Kuyu Motifinin Türk Kültürü, Edebiyatı ve Sinemasına Yansımaları
}

\author{
Reflection of Well Theme to Turkish Folk Culture, Literature \\ and Movie Theatres From the Point of Functionalism
}

\section{Nursel Işık}

\begin{abstract}
Öz
Kuyu, teknolojik imkânların sınırlı olduğu kırsal bölgelerde, suya ulaşmayı kolaylaştıran önemli kaynaklardandır. Bu kaynağın Türk kültüründe, düşünce ve yazın dünyasında gerçek ve mecazî anlamlarda yer edindiği görülür. Kuyu motifinin, günlük hayatta kullanılan deyim ve atasözlerinde, mâni ve türkülerde, masallarda, efsanelerde, menkıbelerde, klasik şiirde, çağdaş edebiyatta maddî anlamının dışında, güçlü bir sembol olarak kullanıldığı da bir gerçektir. Kültür ve edebiyatımızda bu kadar çok kullanımı olan kuyu motifinin, Türk sinemasına yansımaları da paralel bir doğrultuda olmuştur. Drama ve korku filmlerinde, kuyunun maddî, efsanevî ve psikolojik yönlerine vurgu yapıldığı görülür. Makale, kuyu motifinin halk kültürü ve Türk edebiyatından sinemaya aktarılmasını işlevsel açıdan ele almıştır. Çalışmada, maddî bir unsurun görünürde işlevlerini yitirdiği düşünülmesine rağmen, bağlam değiştirmesi sonucu yeni işlevler kazanması kuyu motifi üzerinden analiz edilmeye çalışılmıştır. Çalışma sonucunda kuyunun, su kaynağı olmasının yanı sıra sosyalleşme aracı olması, tabulara kaynak oluşturması, kişinin hatalarını düzeltmesinde şahitlik ederek insanlara faydalı olması, kutsal kabul edilen kişilerin yaşamında dönüm noktası olması, imkânsızlıkları ve çaresizlikleri anlatmak için
\end{abstract}

Geliş tarihi (Received): 15.11.2019 - Kabul tarihi (Accepted): 11.04.2020

* Hacettepe Üniversitesi Türk Halkbilimi Bölümü, doktora öğrencisi, yagangupse@gmail.com, ORCID ID: 00000003-1127-6662. 
bir sembol olması, Klasik edebiyatta sevgilinin güzelliğini anlatmak için bir araç olması, çağdaş yazın ve sinemada "ölümün, cinselliğin, geçmişin, bilinmeyenin" ve karmaşık pek çok duygunun anlatılmasını sağlayan bir metafor olması gibi çok çeşitli işlevleri olduğu tespit edilmiştir.

Anahtar sözcükler: kuyu, halk inancı, kültür, edebiyat, Türk sineması

\begin{abstract}
Well is one of the important sources to reach water in rural areas where technological opportunuties are limited in. It's seen that, this source has a place in Turkish culture, in the world of literature and thought in both real and figurative meanings. The reality is well theme has been using as a powerful symbol in daily life idioms and proverbs, mânis and folk songs, tales, mythes, legends, classical poems, modern literature apart from it's worldly meaning. Therefore, the reflection of well theme to Tukish movie theatre has a parallel direction with its' common using in both Turkish culture and literature. It is seen that; material, legendary and psychological aspects of well are emphasized in dramas and horror movies. In this article, the transfer of well theme from folk culture and Turkish literature to movie theatre is examined with a functionalist point. It is tried to be analysed over the well theme that; although there is a thought of a materialistic factor has lost its' function apparently, with the changing of context, it has gained new functions. With this research besides its' water resource, these functions of well are determined; it is a socialising means, a source for taboo, useful as a witness for people who fix their faults, a milestone in the life of people who are seen as holy figures, a symbol to describe impossibilities and desperations. Also, it is a way to descibe beauty of lover in classical literature, has various functions as a metaphor to impress the "death, sexuality, past, unknown" and complicated feelings in both modern literature and movie theatre.
\end{abstract}

Keywords: well, folk belief, culture, literature, Turkish movie theatre

\title{
Extended summary
}

In the article, it is tried to determine that functions of well theme in beliefs of Turkish folks, literature and movie theatre. With its' concrete function as a water supply, the issues of spiritual needs which provides well theme is analysed. In terms of it's representation both as a concrete object and as an intangable meanings, the well theme's visible and invisible functions can be determined with "functional theory". For this reason, works of Petr Bogatyrev and Bronislaw Malinowski have became useful to give information about functional theory. The work of Bogatyrev which named The Function of Folk Costume in Moravian Slovakia and Malinowski's A Scientific Theory of Culture are taken base for the research. Bogatyrev says in his work, that Slovak traditional costumes have magical, religious, erotic etc. meanings except with the needs for dressing. In this article, the possible invisible functions of well are researched based on Bogatyrev's work. It is indicated that, the function is not a notion which contains only concrete needs but also it contains divine activities in loco citato of Malinowski. Based on this, it is tried to be determined that the role of the well for supply religious requirements besides it supples concrete needs. 
In this work, primarily, the well theme is searched in terms of Turkish mythologies and folk beliefs. It is determined that, the theme is used in Turkish mythology, connected with water soul and the demonic creatures who is believed consists and named as "Kuyu Kizı" (Well Girl). The theme is used like a gate which gives opportunity to pass through the world from another world in Altai Shamanism. In islamic sources there is such an information that, after he is thrown away to a well, Prophet Yusuf swiched between dimensions with the help of divine power and he was teached by God with knowledge and literacy and also dream interpretation.In sufism, the well represents a gate which provides to reach own soul of people. In the work, there is also a myth about role of the well to show up ney (reed flüte). Furthermore, myths about seeing the well as a closelipped and a witness for important secrets, folk implementations are narrated. Well has become a source for various taboos, folk beliefs and implementations related with beliefs.

Idiom, proverb, manî, folk song, tale in Turkish folk literature, the knowledge of well theme is used to describe different meanings is determined. Also in motif, idioms and proverbs "desperation and trap" meanings exist. Is has seen that well head is used as a word form in manîs and folk songs to begin narration and furthermore, is has seen that, the place is described as a meeting place. In folk tales, the well theme had used with many different ways. Wells that a gate to heaven or to another worlds, wells with magical waters, holy wells, wishing wells, wells which full of oil or wine are themes in Turkish tales and in world tales. In tales, well has a function as a gate and food supplier.

In both classical Turkish literature and modern Turkish literature, wells have gotten contemporary and wealthy functions with their function in traditional life. Well theme is a tool to describe magical beauty of lover in classical Turkish poem. The theme is used to describe people's psychology beside it's traditional usage in modern Turkish literature. This circumstance is analysed over three works in Turkish literature which exist in it well theme. The first work analysed is Bir Kara Derin Kuyu written by Nezihe Meriç. In the novel, hardship in life like oppression days, tension in political life, economic difficulties are described over a dark well metaphore which doesn't exist but existence of its' feeling. Second work is a novel written by Bülent Dizdarl1, named Kuyu Mezarları Ülkesi. The novel is about incidents which occur on the ground of tension between Turkish and Greek and corpses who is killed and thrown away the well during the incidents from the end of 1950's until 1970's on Cyprus Island. Well's head is covered to hide corpses and it has a corpses shelterer function in the novel. The well is showed as a concrete existence. The final novel which analysed is Kuyu/İç ve Hiç written by Ünit İnatç1. The novel which is attributed recent history's incidents occur in Cyprus, different meanings of well are used apart from burying corpses. Well that his father's body in there according to the thoughts of novel hero Ahmet, expresses negative and dark feelings. The novel hero expresses the desire of digging a well and burying the psychological dilemmas in his soul and also in his thoughts and with those it is shown that well has a function to hide undesireble thinks in the novel. The prove of sexual function of well is thinking Ahmet a woman's vagina who stands before him to a well top. In addititon to that, the fact that the woman compared her womb to the well with a corpse shows that the archetypal reference was made. At the end of the novel, Ahmet, who entered 
the well he dug in his garden, came out of the well with a child's cry, in a sense, its rebirth. Well acts as a mother's womb.

Finally, functions of well theme in Turkish movie theatre is analysed over various movies in the article. Tütün Zamanı (1959) written by Necati Cumalı and movie with the same name, is the first movie which is analysed. The well theme in this work is so obvious as a concrete way. Leads, Zeliş and Cemal, meet with each other on the well head and decided to marry. In this part, can be seen the social function of the well. Knowledge of essential function of the well as a water supply is given with scene that taking villager water from the well. Countrywomen bear tales about the leads again, on the well head and well has a function for socialized. Second movie is Kuyu (1968) written and directed by Metin Erksan. From the begining of it's generic, in this film, well theme has become a metaphor to represent all the hardness. The lead, Fatma, was abducted by Osman for many times and was obligated to endure his oppressions, because of this situation it shows that there is a well without walls and Fatma is in there. Osman's desire for water, entering the well to kill his thirst and was killed here, indicates that the well has a sexual identity and reference to the mother archetype. Here the well acts as the woman's genitals. The last movie analysed is the short film Киуи (2017). This film conveys the difficulties experienced by trans individuals through the actress, a trans person. While the stifling life conditions experienced by the hero create a well feeling, the corpse of her found in a well at the end of the film and shows that the motif was used to meet a concrete meaning. Apart from these films, it was determined that the well motif was used with the space function that hosts demonic beings in horror films.

In conclusion, well theme has used in Turkish beliefs, folk culture, folk literature, modern Turkish literature and movie theatre are parallel with each other. In the works of new literature and cinema, different functions have been added to the well as well as traditional functions. As a result of the examination, the well motif: It has been determined that it has the functions of being a source of water, being used as a means of punishment, gate connecting the different worlds, education and adulthood, being confidant, symbolizing negative thoughts, being a female genitalia, being a mother's womb, meeting and socializing.

\section{Giriş}

Türk kültüründe geçmişten günümüze önemli bir yeri olan kuyu, genellikle su ihtiyacının karşılanması amacıyla açılan, zemininde su birikintisi olan derin çukuru ifade etmek için kullanılan bir kelimedir. Kuyu kelimesinin "kudug, kudhug, kuyug” şeklinde zaman içinde değişerek günümüzdeki kullanımına ulaştığı tahmin edilmektedir (Ögel, 1978). 11. yüzyılda, Kaşgarlı Mahmud tarafindan kaleme alınan Divanü Lîgat-it Türk'te kelimenin "kudhuğ" (Kâşgarlı, 2013/I), “kuduğ” (Kâşgarlı, 2013/III) gibi kullanımları olduğu görülür. Su kuyularının dışında, yiyeceklerin tazeliğini muhafaza edebilmesi için kullanılan kuyular da vardır. Bunların dışında, suç işleyenlerin ağır şekilde cezalandırılması için yapılan özel kuyular da mevcuttur. Osmanlı döneminde ağır ceza mahkûmlarının hapsedildiği kuyu şeklinde zindanlar bulunduğu (Yıldız, 2015), benzer kuyuların Asya'dan Avrupa’ya pek çok yerde de görüldüğü tarihi kaynaklarda yer alır. Ceza amaçlı kuyular, halk anlatılarında ve yazılı edebiyatta da varlığını sürdürür. Alıp Manaş, Edigey ve Alpamış destanlarında kahramanların 
cezalandırılması için kuyuya atıldığı anlatılır (Köktürk, 2006). Dede Korkut Kitabı'nda Salur Kazan'ın esir alınması, bir kuyuya atılıp kuyu ağzının değirmen taşıyla kapatılması da (Ergin, 2018) kuyunun aynı işlevi karşılamak için kullanıldığını gösterir. Kuyu cezasının yazılı edebiyata yansımasına örnek olarak Edgar Allan Poe'nun Kuyu ve Sarkaç hikâyesi verilebilir. Hikâyede kuyu cezasının ağırlaştırıldığı, adeta bir işkenceye dönüştürüldüğü görülür. Engizisyon kararı sonucu ölüm cezasına çarptırılan bir mahkûmun, içinde çelik bir bıçak şeklindeki sarkaç olan kuyuda, işkence yoluyla öldürülmeye çalışıldığı anlatılır (Poe, 2019).

Kuyu motifi Türk halk kültüründe, halk inançlarında, halk anlatılarında çeşitli şekillerde kullanılır. Klasik Türk şiirinde kuyu motifinin telmih ve teşbih amaçlı kullanıldığı, çağdaş yazınımızda ise çeşitli anlamları içinde barındıran bir metafor olarak kullanıldığı görülür. Kültür ve edebiyatımızdan etkilenen Türk sineması da bu motif ve metaforu çok çeşitli film türlerinde ele almıştır. Özellikle kırsal yaşamı anlatan drama ve korku filmlerinde motifin etkin bir şekilde kullanıldığı görülür. Motifin halk inançlarından, halk kültüründen sinemaya olan yolculuğu esnasında işlevsel açıdan çeşitli benzerlikler ve değişiklikler gösterdiği tespit edilmiştir. Makale, kuyunun somut bir varlıkken nasıl soyut anlamları yüklenen bir varlık haline geldiğini, kuyunun kaybettiği ve kazandığı işlevleri ele almaktadır. Motifin işlevsel açıdan ele alınmasında, kuyunun görünen işlevinin yanında görünmeyen işlevlerinin de bulunması etkili olmuştur. Kuyunun, su kaynağı olarak bilinmesi, başlangıçta onun tek bir işlevi olduğunu düşündürebilir. Fakat bu işlevinin etkin olarak kullanıldığı zamanlardan, teknolojik imkânların artmasıyla söz konusu işlevini yitirmeye başladığı zamana kadar kuyunun görünmeyen işlevleriyle kullanıldığı da bir gerçektir. Günlük hayatta kullanılan deyimler, atasözleri, kuyularla ilgili tabular bunu kanitlar niteliktedir.

Halk kültürünün, edebiyatının, müziğinin, inancının çeşitli değerlerinin analizinde kullanılan işlevsel kuramın, maddi kültür unsurları üzerinde de kullanılabilmesi açısından, makalede işlevsel kuramın kullanılması tercih edilmiştir. Maddi unsurlar üzerinde ilk işlevsel çalışmaları yapan Petr Bogatyrev'in The Function of Folk Costume in Moravian Slovakia adıyla İngilizce’ye çevrilen (1971) eserinde, geleneksel Slovakya halkının giyim kültürünü, "büyüsel, dinsel, ulusal, erotik, günlük ve yaş gruplarına göre kıyafetler" (Dorson, 2011: 39) şeklinde işlevlerine göre gruplandırdığı görülür. Bogatyrev geleneksel kostümün, kişinin içinde bulunduğu durumu yansıtma işlevi olduğunu, giyenin zihinsel yapısını yansıtan bir ayna görevi gördüğünü, bunların yanında estetik bir görünüm de sağlama işlevine sahip olduğunu belirtir (Fjellström, 1974). Burada giysinin, sadece kişiyi fiziki etkenlerden korumak değil, "kostüm" ifadesine uygun olarak, kişinin iç dünyasına ve toplumdaki konumuna göre durumunu yansıtmak gibi işlevlere sahip olduğu anlaş1lır. Bogatyrev’in geleneksel kostümlere olan bu yaklaşımı, çalışmamızda kuyunun görünen ve gizli işlevlerini açıklamak açısından örnek alınmıştır. Bogatyrev'in yaklaşımından bağımsız olarak Bronislaw Malinowski'nin işlev hakkındaki görüşlerinden de makalede yararlanılmıştır. Malinowski’nin, sadece maddi ihtiyaçları karşılayan bir kavram olarak ele almadığı işlev, kişinin kutsal faaliyetlerini de kapsayan bir kavram olarak karşımıza çıkar (Malinowski, 2016). Kuyunun halk inançları içindeki yeri, kuyu ile ilgili oluşan tabular, efsane ve menkıbeler, Malinowski'nin işlev tanımından hareketle ele alınmıştır. Bu yaklaşımdan hareketle kuyunun, manevi açıdan çeşitli ihtiyaçlara cevap verilmesini sağlayan türlü işlevlere sahip olduğu tespit edilmiştir. 


\section{Türk mitolojisinde ve halk inançlarında kuyu motifi}

Türk mitolojisinde su ile ilgili pek çok anlatı vardır. Bu anlatılarda pınar, kuyu gibi suyun olduğu yerlerde, bu yerin sahibi, koruyucusu olan iyelerin bulunduğu kabul edilir. Bu iyelerden biri de Su İyesi/Su Kızı'dır. Bu varlık Türk dünyasının çeşitli bölgelerinde uzun ve dalgalı saçlı, sarışın, mavi gözlü olarak anlatılıp bölgeden bölgeye değişmekle birlikte genellikle vücudunun yarısı balık yarısı insan şeklinde tasvir edilir (Bayat, 2012). Dede Korkut Kitabı'nda bu su iyeleriyle ilgili bir anlatım göze çarpar. Kitapta Tepegöz hakkında bilgi verilirken, onun doğumuna da değinilir. Buna göre Konur Koca Saru Çoban bir pınar başında peri kızlarının toplandığını görür, kızlardan biriyle birlikte olması sonucu Tepegöz doğar (Ergin, 2018). Burada sözü edilen peri kızı da suyun olduğu yerde bulunan doğaüstü varlıklardandır. Anlatılarda bahsi geçen su iyeleri önceki dönemlerde suyu koruma gibi görevlere sahipken, günümüzde daha ziyade korkutucu özellikleriyle bilinmektedir. Örnek olarak Azerbaycan ve Doğu Anadolu'da su iyelerinin Kuyu Kızına dönüşebildiği görülür. Kuyu Kızı, evlerin yakınında bulunan kuyulara çocukların girmesini istemeyen, ürkütücü bir varlık olup, onun bu özelliğinin çocukların kuyuya düşüp boğulmasını engellemek düşüncesiyle (Bayat, 2012), vasıflarına yapılan bir ekleme olduğu tahmin edilir. Benzer durumun yabancı kültürlerde de görüldüğü, çocuklarını kuyudan uzak tutmak isteyen ailelerin kuyunun ruhu, perisi olduğunu söyleyerek onları korumaya çalıştıkları görülür (Çobanoğlu, 2015). Burada suya düşme, boğulma tehlikesinden korunmak için tabu oluşturulduğu belirgindir. Söz konusu tabunun oluşumuyla, çocukların ve belki de bazı büyüklerin zihninde, farklı boyutlarda canlıların yaşadığı, farklı bir dünyanın olduğu bir kuyu fikri oluşur, bu fikir zamanla halk kültürüne sirayet ederek çeşitli halk anlatılarına konu olmaya başlar. Bu anlatılar zamanla kuyunun "bilinmezlik, korkunçluk” gibi kavramların karşılığı olarak, metaforik bir dünyaya kapı açılmasını, kuyunun somut işlevinin soyut anlamları karşılayan daha farklı işlevlere evrilmesini sağlar.

Türk dünyasında etkileri halen görülen Altay Şamanizminde, kuyunun başka dünyalara geçişi sağlayan bir araç olduğuna inanılır. Şamanlar, kuyu yardımıyla bir dünyadan diğerine geçiş yapabilir (Roux, 1994). Celal Beydili, şamanın kullandığı bu özelliğin İslam inancında peygamber ve kutsiyeti olan sofilere verildiğini belirtir. Bu kişiler, yeraltı mağarası ya da kuyuları, "öbür dünya” ile benzer kabul eder ve çilehane olarak bu yerleri kullanırlar. Hoca Ahmet Yesevî'nin 63 yaşında yeraltındaki çilehanesine girmesinin sebebi de bu olabilir (Beydili, 2004). Burada görüldüğü gibi, kuyunun bir dünyadan bir başka dünyaya geçit şeklinde yeni bir işlev üstlendiği görülür. Öyle ki kuyu burada geçit işlevini kazanmakla birlikte, şamanizmden İslam tasavvufuna uzanan süreçte, geçidin boyutunda yenilikler ortaya çıkar. Artık kuyu, kısmen daha somut olan öte dünyaya geçişi değil, kişinin ruhî anlamda huzur bulmasına yardımcı olan manevi bir dünyaya geçişi sağlamaktadır.

İslam inancında kuyu denilince akla öncelikle Harut ve Marut adlı melekler gelir. Bu iki meleğin, kötü niyetle kullanmamak şartıyla halka büyü yapmayı öğrettikleri, bir kadına cinsî arzu duyup bununla ilgili bir suç işlemeleri sebebiyle cezalandırıldıkları anlatılır. Bu cezalandırılma, Babil Kuyusunda baş aşağı asılmak şeklinde olup söz konusu hikâye, Kur'an-1 Kerim'den ayetlerle, çeşitli efsane ve rivayetlerin etkileşimi sonucunda oluşmuştur (Erdem, 1991). Tasavvufta kuyu motifinin cezalandırmanın ötesine geçip çile çekmeye dönüştüğü 
görülür. Şeyh Galip'in Hüsn ü Aşk mesnevisinde kuyu çileyi temsil etmektedir (Pala, 2015). Kuyunun çile çekilen, kişiyi olgunlaştıran özelliğinin zemininde, Yusuf peygamberin, kardeşleri tarafından atılıp üç gün kaldığı kabul edilen su kuyusunun da önemli bir yeri vardır. Zira Yusuf bu kuyuda su olmasına rağmen yılan, akrep vb. canlılarla bir arada bulunmuş, kaldığı müddet boyunca esmâ-i hüsnâyı (Allah'ın güzel isimlerini) dilinden düşürmemiştir (Pala, 2015). Adem Balkaya, kuyu motifiyle ilgili bir makalesinde, Yusuf peygamberin kuyuya atılmasını, onun eğitilmesiyle birlikte ele alır. Kuyunun erginleştirme işlevi vardır ve Yusuf bu sayede, kuyuda kaldığı süre zarfında boyutlar arası geçiş yaparak, tanrının kendisine bahşettiği ilim, okuma-yazma ve rüya tabir etme özelliklerini kazanır (Balkaya, 2014).

Tasavvufî anlatılardan bir başkası olan ney çalgısının hikâyesinde de su kuyusunun önemli bir yeri olduğu görülmektedir. Feridüddin Attar neyin hikâyesini Muhammed peygamber zamanına dayandırmaktadır. Buna göre, Muhammed, kendinden sonraki dönemlerde halife olacak olan, yeğeni Ali'ye ilâhî aşkın esrarı ve hakikatiyle ilgili bir sır verir. Ali bu sırrın ağırlığını taşıyamayıp Medine'nin dışına çıkar, sırrı boş bir su kuyusuna anlatır. Boş kuyu bu sırrın etkisiyle suyla dolar, taşar, etrafında kamışlar büyür. Bir çoban bu kamışlardan birini keser, çeşitli yerlerinde delikler oluşturarak ney çalgısını elde eder ve ona üfleyerek ses çıkarır. Muhammed bu ney sesini duyar ve yeğenine, verdiği sırrını tutup tutmadığını sorar. Ali de sırrı kuyuya söylediğini anlatır (Pakalın, 1993). Bundan sonra bu sır neyin üflenmesiyle dünyaya yayılır. Burada kuyu, sır saklayan, hatta sırrın ağırlığıyla taşan, canlı bir varlık gibi anlatılır. Kuyu, insanın sırdaşı işlevi görür.

Halife Ali'nin boş su kuyusuna sır vermesi gibi insanlar da kuyulara sır vermiştir. Burada kuyunun içindeki suyun da etkili olduğu unutulmamalıdır. Çünkü eski Türk kültüründe, su canlı bir varlık olarak görülür. Dede Korkut Kitabı'nda, Salur Kazan'ın suya seslenmesi, ordusuna dair haber sorması (Ergin, 2018) buna verilebilecek örneklerdendir. Türk kültüründe su kuyusuna sır verilmesinin yanında, yemin edilmesi, tövbe edilmesi gibi uygulamalar da görülür. Konuyla ilgili olarak Pertev Naili Boratav, Adana'ya ait bir uygulamayı anlatır. Buna göre; bir kadının ilk üç çocuğundan sonra doğan bütün çocukları ölmüştür. Kadının dokuzuncu gebeliği sırasında, üçüncü çocuğu bir kuyuya götürülmüştür. Çocuk kuyu başında "bir daha baş yemem” diye bağırarak 7 kez tövbe ettirilmiştir. Bu çocuğun ömrü boyunca hiçbir hayvanın başını yemediği belirtilmiştir (Boratav, 1984). Burada hayvan başının yenmemesi önemli olduğu gibi, çocuğun kuyuya yemin etmesi oldukça dikkat çekicidir. Kuyunun yemin kabul etme ya da yemine şahit olma gibi bir özelliği olduğu görülmektedir. Kuyunun bir insan gibi değerlendirilmesi, yapılan yemine sadık kalınıp kalınmayacağını kontrol edecek gibi tasavvur edilmesi, onun kontrol mekanizması gibi değerlendirildiğini gösterir. Yahut tutulmayan yemini, asıl cezalandırıcıya bildirecek gibi düşünülür. Bu açıdan kuyunun kutsal bir varlık ya da kutsala giden yolda önemli bir basamak işlevi gördüğü düşünülebilir. Anadolu' da bazı kuyuların şahitliğin dışında, dileklerin yerine getirilmesinde etkisi olduğuna da inanılır. Sivas'ın Zara ilçesinde bulunan Bahtiyar adlı su kuyusunun, önceki zamanlarda pek çok ziyaretçiye ev sahipliği yaptığı, bir dileği olanların sabah bu kuyunun başına gelip kuyudan su içip ardından "bahtım açılsın" diye üç kez bağırıp dileklerini kuyuya söyledikleri bilinir (Demir, 2013). Burada kuyunun dileklerin kabul edilmesinde etkili bir varlık olmayı işlev edindiği görülür. Şanlıurfa'da yaşatılan bir inanç, su kuyularının dinî anlamda değerinin 
de olabileceğini göstermektedir. Buna göre; Urfa'yı yöneten bir kişi, tedavisi olmayan bir cilt hastalığına tutulur, İsa peygamberi bu hastalığını iyileştirmesi için şehrine davet eder. İsa şehre gelemese de yüzünü sürdügü ve siluetinin olduğu bir mendili bu yöneticiye gönderir. Mendil yöneticiye götürülürken, günümüzde Eyüp Peygamber Makamı olarak anılan yerde yanlışlıkla bir kuyuya düşürülür. Kuyuda İsa'nın yüzü belirir. Mendil kuyudan alınır yöneticiye götürülür. Hasta adam mendilin tenine değmesiyle iyileşir. Bu mendilin düşürüldüğü kabul edilen kuyu başı, Hristiyanlar tarafından kutsal olarak kabul edilmektedir, her yıl Paskalya Yortusunun yirminci gününde buraya gidilerek dilekler dilenmektedir (Kurtoğlu, 2008). Burada da kuyunun, mendilin etkisiyle kutsiyet kazandığı, bir hac mekânı olarak, üzerine yeni bir işlev yüklendiği görülür.

\section{Türk halk edebiyatında kuyu motifi}

Kuyu motifi deyim, atasözü, mâni, türkü, masal vb. edebî türlerde varlığını sürdürmektedir. Bir işin imkânsızlıklar ve zorluklar içinde yapıldığını belirtmek için kullanılan "iğneyle kuyu kazmak", sonu belirsiz işleri anlatmak için kullanılan "dipsiz kuyu” deyimleri günlük hayatta yaygın olarak kullanılırlar. İnsanlara kötülük yapmak için çabalayan kişilerin ilk zararı kendilerinin gördüğünü anlatmak amacıyla kullanılan "El için kuyu kazan, evvela kendisi düşer." atasözü, kuyunun somut bir varlık olmasının ötesinde, "tuzak" anlamı taşır. Bu atasözü ve deyimlerde kuyunun derinlik özelliği, "belirsizlik, zorluk, tehlike” gibi anlamlarla farklı bir işlev kazandırılarak kullanılmıştır.

Halk edebiyatının söylemelik türlerinden olan mânilerde kuyu motifinin genellikle, aşkın anlatılmasında yardımcı unsur olarak kullanıldığı görülür. Bazı mânilerde âşık kuyu motifini ilk mısrada, konuya giriş amaçlı kullanır. Böylelikle kuyu mânilere giriş yapmayı sağlayan bir kalıp işlevi görür. Bazı mânilerde ise âşık, sevgiliyle buluştuğu yer olan kuyu başında, içinde bulunduğu ruh halini dile getirir. Aşağıda bu kullanımlarla ilgili mâni örnekleri yer almaktadır:

"Kapisinda kuyu var

Ab-1 Kevser suyu var

Olmuşam yâr delisi

Gören der ki huyu var” (Kara, 1993: 97)

"İndim kuyu dibine

Baktım suyun rengine

Anneler kız doğurmuş

Vermiyor sevdiğine" (Özyürek, 1991: 18)

"Kuyu dibinde kuyu

Uyu sevgilim uyu

Seni sarhoş dediler

İçtiğin üzüm suyu" (Gözükızıl, 2013: 226) 
“Gittim kuyu başına

Başım değdi taşına

Anası kurban olsun

Kızının oynaşına" (Kilisli, 2001: 55)

Halk türkülerinde su kaynakları ve özellikle de kuyu başları, âşıkların buluşma yeridir. Eve su taşıma işi genellikle evdeki gençlere verildiği için, genç kız ve erkeklerin kuyu başında karşılaşması, tanışması, sohbet etmesi, âşık olması mümkündür. Kuyunun gençlerin buluşup sohbet ettiği bir mekân işlevi görmesi, türkü sözlerine de yansır. Aşağıda yer alan türkü metni, kuyunun bu işlevini anlatır niteliktedir:

"İndim kuyu dibine

Baktım suyun rengine

Yüz bin liralık kızıdım

Düşemedim dengime

A yarım neredesin

Gözlerime perdesin

Çok aradım çok sordum

Varmadığım yerdesin

El edersem cama gel

Göz edersem dama gel

Hiçbir şeyler bilmezsen

Desti al da suya gel” (Türk Halk Müziği Sözlü Eserler Antolojisi-2, 2000: 486).

Halk edebiyatında kuyu motifinin kullanıldığı bir başka tür, masaldır. Zengin motif dünyasını bünyesinde barındıran masallarda, kuyu ile ilgili çok çeşitli anlatımlar bulunur. Kuyuların kendileri olağanüstü özelliklere sahip olabildiği gibi, içlerinden çıkan varlıklar da fizik ötesi özelliklere sahip olabilir. Stith Thompson'ın Motif-Index of Folk-Literature adlı eserinde, kuyu motifiyle ilgili çok sayıda kullanım mevcuttur. Cennet kuyusu, aşağı dünyaya geçidi olan kuyu, öte dünyadaki kuyu, yaşam ve ölüm kuyusu, nehirlerden kaynağını alan kuyu, denizin altındaki kuyu, kutsal kuyu, bir azizin kazdığı şifa kuyusu, büyülü kuyu, suyu dans eden kuyu, dilek kuyusu, kehanet ve işaretlerle dolu kuyu, renkli sularla dolu kuyu, yağ-şarap-bal dolu kuyu, kan kuyusu ve bunun gibi pek çok kuyu türü bu eserdeki yerini alır (Thompson, 1955-1958). Bu kuyu motiflerinin bir kısmı Türk masallarında da bulunur. Dibinde farklı bir dünyanın bulunduğu kuyu motifinin Şahmeran adlı masalda bulunması bu duruma bir örnektir. Lokman adlı genç, içinde bal bulduğu bir kuyudaki deliği bıçağıyla kazırken, Şahmeran'ın yaşadığı farklı yaşam alanını keşfeder ve bir süre onunla birlikte yaşar, ardından yeryüzüne çıkar (Şimşek, 2001). Bir başka masalda, kahramanın ak ve kara dünyaya açılan bir kuyuya girdiği, bu dünyalarda olağanüstü hayvanların ve canlıların olduğu görülür (Boratav, 1969). Bu kullanımlarda kuyu motifinin bir geçit işlevi gördüğü belirgindir. 
Thompson'ın eserinde geçen, içinde farklı sıvıların var olduğu kuyu motifine örnek olarak, bir Kıbrıs masalında anlatılan konyak, şarap ve zivaniya (saf alkol) dolu üç kuyu verilebilir (Sakaoğlu, 1983). Bu kuyular, masal kahramanının iyilik yapması sonucu Hızır'dan dilek dilemesiyle oluşur, Hızır'a kötülük yapması sonucu da yok olur. Burada kuyu, Hızır'ın marifetiyle var olur ve yok olur. Bu da Thompson'ın eserinde yer alan, azizin kazdığı kuyuyla bir bakıma benzerlik gösterir. Söz konusu kuyu, besin ihtiyacı karşılama işlevini taşır. Bu ve benzeri işlevlere sahip kuyular, çok sayıda masalda yer alır.

\section{Klasik ve yeni Türk edebiyatında kuyu motifi}

Halk edebiyatından örneklerini verdiğimiz kuyu motifinin Klasik Türk edebiyatında ve yeni edebiyatta, benzer ve farklı işlevleri taşıyan karşılıkları mevcuttur. Klasik Türk edebiyatında, kuyu motifi aracılığıyla telmih ve teşbih yapıldığı görülür. Sevgilinin büyüleyici bir güzelliğe sahip olduğunun anlatıldığı bazı beyitlerde, Harut ve Marut adlı büyü yapan meleklerin hikâyesine telmihte bulunulur. Bu iki meleğin, güzel bir kadına kapılıp hatalı işler yapması ve tanrı tarafından kuyuya asılarak cezalandırılması, sevgilinin söz konusu kuyudaki büyücülerden biri olduğunun iddia edilmesiyle bağlantılı olarak ele alınır (İnce, 2007). Böylece hem geçmişteki bir olaya telmih yapılır hem de sevgili büyücüye benzetilerek teşbih yapılır. Kuyu bu kullanımlarda, söz sanatının yapılmasına yardımcı olan unsur işlevi görür. Divan şairlerinden Nedim'in, konuyla ilgili bir beyti ve metnin günümüz Türkçesine aktarımı aşağıda verilmiştir:

"Gamze-i fettânını koydun ki yıktı 'âlemi

Bahse dalmışken çeh-i Bâbil’de câdûlarla sen” (Levend, 2017: 223)

Günümüz Türkçesine aktarımı:

"Sen Babil kuyusunda cadılarla sohbet ederken fettan yan bakışın da âlemi yıktı, harap etti” (İnce, 2007: 112).

Klasik edebiyatta sevgiliyi anlatmak için kullanılan kuyu motifinin yeni edebiyata daha farklı işlevleri üzerinde taşıyarak dahil olduğu görülür. Kuyunun bilinmeyenlerle dolu derinlikleri çağdaş yazarların bir kısmında kaosa girmişlik etkisi uyandırır. Bazı durumlarda kuyu, kahramanı içine çekerken bazılarında ise kahramanın kuyuya inmeyi istediği görülür. Kahramanın istemsizce bir kuyuda olduğunu düşünmesine Nezihe Meriç’in Bir Kara Derin Kuyu hikâye kitabı örnek verilebilir. Yazar, 1980’li yıllarda yazdığg ve yirmi yıl öncesine de yer verdiği hikâyelerde, dönemin siyasî gerginliklerine, yaşanan maddi zorluklara, insanların olumsuz anlamdaki değişimlerine, eski güzel günlere olan özlemine, yazmakla ilgili sorunlarına değinir. Değinir, çünkü bunları çok derin ve vurgulu bir şekilde anlatmadan, günlük hayatın küçük parçaları gibi küçük cümlelerle, kısa sözlerle ifade eder. Talat Sait Halman, eserin başında yazarın "Yaşadığımız şu günleri anlamaya çalışmak, beni çok yordu. Yazmak, giderek büsbütün zorlaşıyor benim için” (Meriç, 2019: 217-218) cümlelerine atıf yaparak, Meriç gibi oldukça duyarlı bir yazarın, bulunduğu zulüm, kargaşa ve umutsuzluk dolu ortamın, yazmasına engel oluşturduğuna küçük bir vurgu yaptığını belirtir (Halman, 1991). Meriç'in yaşadığı zor şartlar ve yazı yazamayışı onun hikâyelerinin kara, derin bir kuyuda yazıldığı hissini verir. Burada kitaba ismini de veren kuyu, umutsuzlukla dolu ortamı anlatan bir metafor işlevi görür. 
Kıbrıs’ta, kuyu kavramının karanlık bir geçmişi ve kayıp vatandaşları çağrıştırdığı bilinir. Rum ve Türk halklarının yaşadığı adada, 1950'lerin sonlarından 1970'li yıllara kadar süren, terör ve yer altı örgütlenmesi kaynaklı çatışmalar, katliamlar yaşanmıştır. Bu durum Kıbrıs Türk edebiyatına da yansır. Yaşanan olaylarda cesetleri kuyulara atılan vatandaşların, yıllar sonra bulunan naaşlarının ve olaylara şahitlik eden halkın yaşamının edebi eserlere konu teşkil ettiği görülür. Kuyuya atılma olgusunu somut gerçekliğiyle ele alan eserlere, Bülent Dizdarlı'nın 2014'te yayımlanan Kuyu Mezarları Ülkesi romanı örnek verilebilir. Romanda, dedesinin Rum teröristler tarafından öldürülüp yıllar sonra bulunduğuna dair haber alan yaşlı bir kadının, yaşadığg yer olan İngiltere'den Kıbrıs'a kısa süreli dönüşü anlatılır. Yaşlı kadın, geriye dönüş tekniği kullanılarak Kıbrıs'ın çatışmalarla dolu günlerine, dedesini ve eşini kaybettiği günlere döner. Eserde kuyu, bir metafor değil doğrudan somut bir varlık olarak ele alınır. Kuyunun, görülmesi istenmeyen şeyleri kapatan, saklayan bir işlev üstlendiği görülür (Aylanç, 2013).

Kuyu motifi ekseninde oluşturulmuş bir başka eser ise Kıbrıslı yazar Ümit İnatçı’ya ait olan, 2016'da yayımlanan Kuyu/ İç ve Hiç romanıdır. Roman, kuyunun somut bir varlık olmanın yanı sıra içinde pek çok derin anlamı taşıyan çok yönlü bir metaforik anlatımın kullanıldığı anlam zenginliğiyle dolu bir eserdir. Romanın kahramanı Ahmet, daha önce de bahsi geçen, kuyuya inmeyi isteyen kahramanlardandır. Ahmet'in yıllar sonra Kıbrıs'a dönüşü ve babasının gömülü olduğu kuyuyu arayışı, bu arayış içinde kendi duygu dünyasında meydana gelen iniş ve çıkışlar eserde anlatılır. Kahraman adaya geldiğinde, kaldığı evin bahçesine bir kuyu kazmaya başlar. Kendisini ve çevresini anlamlandırmak amacıyla kendi zihnindeki kuyuya inmesini kolaylaştırmak için kazdırılan bu kuyu, kahramanın kendi derin, çıkmazlarla ve ikilemlerle dolu düşünce dünyasını da temsil eder. Metin Karadağ, yazarın kuyu kazdırmakla, bireyin içindeki kuyuların kazılarak "gize yüklenmiş olanların” aydınlığa çıkarılmasını dilediğini belirtir (Karadağ, 2017). Romanda, eserin kahramanı Ahmet, Kıbrıs’a borçlu olduğunu fakat bir yandan da Kıbrıs’tan öç alması gerektiğini düşünür. Ahmet bu öç duygusunun, içinde bir kuyu kazdığını, kendisinin de bu kuyuya öfkesini, iç bulantılarını, baş dönmelerini hapsettiğini belirtir. Burada kuyunun, görmek istenmeyen şeylerin gömüldüğü bir kuyu işlevine sahip olduğu görülür. Ahmet'in öfkesi, içindeki kuyuyla kalmayıp bahçeye kazdığı kuyuyla da ilişkilendirilir. Ağabeyine, kazdıkları kuyuya ya öfkesini ya da babasının katilini gömeceğini söyler. Burada kuyu soyut bir halden somut bir hale geçerek, istenmeyenin ortadan kaldırılması, gömülmesi işlevinin sürdüğünü gösterir. Yıllar önce babasının öldürülüp atıldığı kuyu ise Ahmet için kirli ve kötü düşünceleri ifade eder, babasıyla ilgili bilinmeyenleri "dibi karanlık kuyu” (İnatçı, 2016: 107) olarak adlandırır. Burada kuyunun, karanlık ve olumsuz duygulara ev sahipliği yapan bir mekân işlevini taşıdığı görülür. Romanda Ahmet'in, Rozana adlı bir kadının rahim ağzını kuyu ağzına benzettiği bir bölüm vardır. $\mathrm{Bu}$ da kuyunun cinsel açıdan bir işlevi olduğunu gösterir. Birlikte olacağı kadının vajinasına bakan kahramanın, bunu içinde kayıp bir cesedin var olduğu bir kuyuya benzetmesi Jung'un anne arketipini akıllara getirir. Burada, Jung'un Dört Arketip adlı eserine, anne arketipinin tezahürlerinden olan kuyuya bir atıf vardır (Jung, 2019). Kuyu, rahim işlevi görür. Rahmin içinde var olan kayıp cesedin kahramanın kendisi olduğu ortadadır. Çünkü Ahmet, ölmediğini öğrendiği babasıyla karşılaştıktan sonra, geride kalan kuyunun kişileşmiş bir varlık, kendisi gibi kayıp bir kişilik olduğunu söyler. Burada kuyunun yaşayan bir varlık olması, 
hem Türk halk inançlarıyla paralellik taşır hem de buna yeni, kişisel anlamlar yüklenir. Kuyu adeta bir insandır. Romanın sonunda kahramanın kuyunun başına geçip doğmuş olmanın pişmanlığını ve yeniden doğmanın arzusunu hissetmesi, soyunup kuyuya girmesi ve vücudu soğuyana kadar burada beklemesi anne arketipine yapılan göndermelerdir. Kuyudan bir çocuk ağlamasıyla, çamurlu ve yaralı şekilde çıkan Ahmet, annesinin resmine bakıp ağlar ve hayatına devam eder. Böylece rahim işlevi gören kuyunun, bir anneye dönüşerek, doğum yoluyla yaratma işlevi üstlendiği görülür.

\section{Türk sinemasında kuyu motifi}

Türk sinemasında kuyu motifinin çeşitli şekillerde kullanıldığı filmler mevcuttur. Bu filmlerin Türk halk inancı, kültürü, edebiyatı ve çağdaş edebiyattan uzak olmayan bir şekilde kuyu motifine yer verdiği görülür. Sinemanın kırsal hayatı konu edinen filmlerinde kuyu motifinin, mekânın yerelliğine vurgu yapılması için kullanıldığı pek çok sahne mevcuttur. Bu filmlerde kuyu hem bir su kaynağı hem de farklı işlevleri bünyesinde taşıyan bir mekân özelliği gösterir.

Necati Cumalı'nın aynı adlı romanından uyarlanan Tütün Zamanı ${ }^{1}$ (1959) filminde, kırsal yaşamın önemli parçalarından biri olan kuyunun birden fazla işlevi olduğu görülür. Cemal ve Zeliş adlı iki gencin aşkını konu alan filmde, gençlerin birlikteliğini etkileyen anların yaşanması ve önemli kararların alınması, büyük ölçüde kuyu başında gerçekleşir. Filmde kuyu motifinin ilk kullanıldığı sahne iki gencin tesadüfen karşılaştığı anı ele alır. Zeliş elinde testiyle kuyu başına gider. Kuyuya iple bağlı kovayı bir süre çektikten sonra kovanın, onu tamir etmeye çalışan Cemal'in elinde olduğunun farkına varır. Cemal, kovayı tamir etmeye çalıştığını söyler ve ardından gençler arasında sohbet başlar. Zeliş, Cemal'in maharetinden söz eder, ardından mâni yazmayı bilip bilmediğini sorar, Zeliş’e âşık bir genç olan Yaşar'ın gelmesiyle sohbetleri son bulur. Söz konusu sahnede kuyu başı, gençlerin tanışıp, sohbet etmesini sağlayan bir mekân işlevi gösterir. Köydekilerin meraklı bakışlarından ve ebeveynlerinin göz hapsinden uzak bir şekilde sohbet imkanı bulan gençler için kuyu başı, tanışma ve buluşma noktası işlevi görür. Bu işlev, mâni ve türkülerde kuyu motifinin kullanımıyla benzerlik gösterir.

Tütün Zamanı filminin, kuyu etrafında geçen bir diğer sahnesi, köyün kadınlarının kuyudan su çekerek testilerini doldurduğu, sohbet ettiği sahnedir. Zeliş’in kız kardeşi Rabia, kuyudan su çeken köylü kadınların, ablası hakkında dedikodu yaptıklarını görür. Onlarla tartışır. Ardından Zeliş de kuyu başına gelir. Rabia su dolu kovayı kuyudan çıkarırken "Elimden gelse şu kuyuyu kör ederim” der. Zeliş nedenini sorar. Rabia "Kuyu başı değil, dedikodu başı. Demediklerini bırakmadılar" şeklinde cevap verir. Filmin kuyuyla ilgili bu ikinci sahnesi, kuyu başının köyde olup bitenin konuşulduğu, kimi zaman dedikodu yapıldığı bir mekân olarak kullanıldığını gösterir. Rabia dedikoduların bitmemesini kuyunun su dolu olmasına, insanların etrafında toplanmasına bağlayarak onun kör olmasını, suyunun bitmesini ister. Böylece köylünün toplandığı bir mekânı elinden almış olacaktır. Görüldüğü gibi kuyu köylünün sosyalleşme alanı olma işlevini yüklenir. Kuyu köyün bir nevi nabzıdır. Köydeki önemli gelişmelerin yayılma noktalarından birisi durumundadır. 
Filmin bir sonraki kuyu sahnesi Zeliş'in babası Recep ve Zeliş'le evlenmek isteyen Bekir arasındaki konuşmanın geçtiği bölümdür. Bu sahnede Recep, kızının Cemal'le olan ilişkisinin kendilerine ekonomik olarak zorluk yaşatacağını, tütün hasadında Zeliş olmazsa ortada kalacaklarını anlatır. Bunları yaparken bir yandan da kuyudan su çekip içer, elini ayağını yıkar. Ardından Bekir, Cemal'le Zeliş'in evlenmemesi için yaptığı planı Recep'e anlatır. Konuşmanın sonunda Recep elindeki kovayı Bekir'e verir, Bekir de kovadan su içer, ardından kuyunun yanından ayrılırlar. Filmde kuyunun başında geçen bu sohbet, kuyu başının gizli işlerin de konuşulduğu tenha bir yer olduğunu gösterir. İki adamın konuşması kuyunun şahitliğinde gerçekleşir.

Filmde Cemal ile Zeliş'in hayatları için en önemli kararlardan olan evliliği de kuyu başında verdikleri görülür. Kendisini kaçırmaya çalışan Bekir ve adamlarından kurtulan Zeliş koşarak kuyu başına gelir, Cemal'e kaçırılmaya çalışıldığını söyler. Cemal bir an önce evlenmeleri gerektiğine dair cümleler söyleyip Zeliş’in elini tutar ve hızla kuyu başından uzaklaşırlar. Bu kaçışın ardından kovalayanlar (Recep, Bekir ve adamları) da kuyu başında durur ve ne yapacaklarına dair bir konuşma yaparlar, ardından uzaklaşırlar, sahne burada son bulur. Kuyu başı, iki gencin evlilik kararını verdiği yer olur.

Tütün Zamanı filminde kuyu buluşma, sosyalleşme, tenha olması sebebiyle sır saklama gibi işlevlerle karşımıza çıkar, kuyunun sembolik yönü bu filmde kuvvetli değildir. Burada daha çok görünen, somut işlevler vardır. Kuyu motifinin daha soyut ve metaforik anlamda kullanıldığ 1 filmlere ise Metin Erksan'ın senaryosunu yazdığ 1 ve yönettiği Kuyu² (1968) filmi örnek verilebilir.

Kuyu, Metin Erksan'ın okuduğu gazete haberinden ilham alarak yazdığı ve yönettiği bir filmdir. Filmde yaşanan olayların asıl kahramanı olan kadın, bir adam tarafından beş defa kaçırılır. Her kaçırma sonrası hapse giren adam kadının peşini bırakmaz, beşinci defa kaçırdığgında ise kadın tarafından, indiği kuyuda üzeri taşla örtülerek öldürülür. Kadın bu cinayet sonrası hapse girer (Altıner, 2005). Erksan senaryoda değişikliğe giderek kadının kaçırılma sayısını üçe indirir, Taşpınarlı İdamlık Mehmet gibi yeni kahramanları senaryoya ekleyerek Türk sinemasına yeni bir yapıt kazandırır.

Kuyu filmi genç bir kız olan Fatma’nın, sevmediği Osman tarafından defalarca kaçırılmasını, yaşadığı birtakım olaylar sonrasında Osman’ı bir kuyuda öldürmesini anlatır. Filmin başlangıç jeneriğinde bir kuyunun içinden, kuyunun aydınlık ağzının gösterildiği, sol alt köşede ise "Kadınlara iyilikle davranın" şeklindeki Kur'an ayetinin yazılı olduğu görülür. Bu görüntü, filmde kadın ve onun içinde bulunduğu, duvarları görülmeyen, soyut dipsiz kuyuyu sembolize eden ilk sahneyi oluşturur. Motifin filme adını vermesi ise Fatma'nın yaşadığı çıkmazlarla dolu hayat, Osman’ı öldürme şekli ve kuyu başında intihar etmesiyle ilgilidir. Filmde Fatma'nın Osman tarafından ilk defa görüldüğü, kaçırılmaya çalışıldığı sahnelerde sık sık nehir ya da su birikintisi olduğu görülür. Filmi psikanalitik açıdan ele alan Mehmet Oğulcan Turan, bu su sahnelerini Osman'ın çalkantılı ve arzulu ruh haliyle ilişkilendirir (2013). Filmin sonunda ise bir kuyu sahnesi mevcuttur. Bu sahnede Osman'1n, bir iple bağladığ1 Fatma'yı yukarıda bırakıp su kuyusunun içine girdiği, serinlemeye çalıştığ1 görülür. Bağlı olduğu ipi açan Fatma, etraftaki taşları alarak Osman'ın üzerine atar ve kuyu kapanıncaya kadar bunu yapmaya devam eder. Filmin mitolojik yönünü incelediği makalesinde 
Aysun Akıncı Yüksel, burada kuyunun dar, karanlık ve ıslak çeperinin kadının cinsel organına bir gönderme olduğunu, filmde kuyunun çekim açılarının da bu cinselliğe göndermede bulunduğunu ifade eder (2016). Kuyu ile cinsel organ arasındaki bu benzetme, Jung'un anne arketipleriyle de uyumludur. Kuyu sahnesi hakkında Turan, Osman'ın kuyuya inişini (suya ulaşmasını) arzularının doruk noktasına ulaşması şeklinde açıklar. Ona göre kuyu, arzuların çevrelemiş ve durgunlaşmış son halidir. Burada arzulanan şeye, suya ulaştı̆̆ düşünülen Osman'ın, arzuladığ 1 bir diğer şey olan Fatma tarafından öldürülmesi, Osman'ın arzularıyla birlikte yok olması anlamına gelir (Turan, 2013). Osman'ı öldüren Fatma’nın, kuyu başındaki serenin ${ }^{3}$ ucuna ip bağlayarak intihar etmesi ise derin ve karanlık bir kuyu gibi olan ömrünü sonlandırdığı sahnedir. Erksan, filmin yayınlanmasından yıllar sonra verdiği bir röportajda, Fatma'nın ataerkil düzene karşı çıkan güçlü bir kadını, onun direnişini anlatmaya çalıştığını belirtir. Ayrıca film tekrar çekilecek olsa Fatma'nın Osman'1 taş atarak öldürmesine ve kuyu başında intihar etmesine müsaade etmeyeceğini anlatır (Altıner, 2005). Böylece kuyuya yüklenen anlamlarda değişiklik olabileceği görülür. Kuyu filminde kuyu, su sağlama işlevinin yanında, çaresizlikle dolu bir yaşama işaret eden bir metafor işlevi de görür. Aynı zamanda kadının cinsel organına üstü kapalı atıf yapılarak cinselliği çağrıştıran bir nesne işlevini de bünyesinde bulundurur.

Kuyu motifinin uzun metrajlı filmlerin yanında, kısa filmlerde de kullanıldığı görülür. Hayatın zorlukları, maddi sıkıntılar, insan haklarının ihlali gibi konularda kuyu motifinin somut ya da sembolik şekliyle kullanıldığı Türk kısa filmleri vardır. Bunlardan Kuyu ${ }^{4}$ (2017) adlı kısa film, trans bireylerin karşılaştıkları zorlukları anlatır. Filmin kahramanı olan trans birey, polisle yaşadığı çatışmayı, onlarla yaptığı konuşmayı, yatağının yanında duran cansız mankene anlatır. Telefonla aranmasının ardından akşam sokağa çıkar, sokakta sakallı bir adamın gölgesi görünür ve ardından kahramanın, bir kuyunun içinde olan cesedi gün ışığının eşliğinde görülür. Bu filmde kuyu hem somut bir varlık hem de kahramanın içinde bulunduğu hayat şartlarının boğuculuğunu temsil eden bir metafor işlevi görür.

Yukarıda anlatılan drama tarzı filmlerin dışında, Türk korku filmlerinde de kuyu motifinin kullanılmaya başlandığı görülür. Bu filmlerde kuyu büyük ölçüde, cinlerin mekânı olan, insanların uzak durması gereken bir yer olarak anlatılır. Kırsal bölgelerde geçen korku filmlerinde bu motif kullanılmakla birlikte, Türk korku filmlerinin çoğunun şehir yaşamıyla ilgili olması, senaryo yazarlarının kuyu motifini farklı gözlerle ele alamaması, motifin farklı şekillerde kullanımının ve kuyuya başka işlevler atfedilmesinin önünde bir engeldir. Türk korku filmlerinde kuyu genel olarak, fizik ötesi varlıkların yaşadığı bir mekân işlevi görür.

\section{Sonuç}

Yapılan çalışmada kuyu motifinin Türk halk inancında, kültüründe, edebiyatında, yazın ve sinema dünyasında birbiriyle bağlantılı ve farklı işlevlere sahip olduğu tespit edilmiştir. Kuyunun görünen ve gizli işlevleri, manevî ihtiyaçlara cevap verme işlevi olduğu görülmüştür. Sonuç olarak kuyu motifinin; su kaynağı olma, ceza aracı olarak kullanılma, bir dünyadan başka bir dünyaya geçit olma, eğitim ve erginleştirme, sırdaş olma, hac mekânı olma, Klasik edebiyatta söz sanatlarının yapılmasında araç olarak kullanılma, besin ihtiyacı karşılama, görülmek istenmeyen şeylerin ortadan kaldırılmasına yardımcı olma, karanlık duygu 
ve düşüncelere ev sahipliği yapma, kadın cinsel organı olma, rahim işlevi görerek yeniden doğuşa yardım etme, buluşma ve sosyalleşme mekânı olma işlevleriyle kültürümüzde, edebiyatımızda, sinemamızda yaşatıldı̆̆ı tespit edilmiştir. Çağdaş edebiyat ve sinemamızda kuyu motifinin Türk inanç ve kültürüyle, halk edebiyatından izler taşıdığı, bunun yanında motife yeni işlevler kazandırıldığı görülmüştür.

\footnotetext{
Notlar

1 Arıburnu, O. M. (Yönetmen). (1959). Tütün zamanı [Film]. Duru.

2 Erksan, M. (Yönetmen). (1968). Киуu. [Film]. Ortak.

3 Seren: Kuyudan su çekmekte kullanılan kaldıraca benzer bir aygıt. sozluk.gov.tr

4 Çelik, G. (Yönetmen). (2017). Kuyu [Film].
}

\section{Kaynaklar}

Altıner, B. (2005). Metin Erksan sinemast. İstanbul: Pan.

Aylanç, M. (2017) Kıbrıs Türk romanı eserler sözlüğü. Ankara: Uluslararası Kıbrıs Üniversitesi.

Bayat, F. (2012). Türk mitolojik sistemi 2. (2. bs.). İstanbul: Ötüken.

Beydili, C. (2004). Türk mitolojisi-Ansiklopedik sözlük. E. Ercan (Çev.). Ankara: Yurt.

Bogatyrev, P. (1971). The function of folk costume in Moravian Slovakia. Paris: Mouton.

Boratav, P. N. (1969). Az gittik uz gittik. Bilgi.

Boratav, P. N. (1984). 100 soruda Türk folkloru. (2. bs.). İstanbul: Gerçek.

Çobanoğlu, Ö. (2015). Türk halk kültüründe memoratlar ve halk inançları. (2. bs.). Ankara: Akçağ.

Demir, N. (2013). Türk efsaneleri. İstanbul: Edge Akademi.

Dizdarlı, B. (2014). Kuyu mezarları ülkesi. Lefkoşa: Khora.

Dorson, R. M. (2011). Günümüz folklor kuramları. S. Gürçayır-Y. Özay (Çev.). (2. bs.). Ankara: Geleneksel.

Erdem, S. (1991). "Bâbil” maddesi. Türkiye Diyanet Vakfi İslam Ansiklopedisi, S. 4, ss. 392-395.

Ergin, M. (2018). Dede Korkut Kitabı I-II. (2. bs.). Ankara: TDK.

Gözükızıl, Ö. (2013). Çanakkale halk kültürü (I). Çanakkale Onsekiz Mart Üniversitesi.

İnatçı, Ü. (2016). Kuyu / İ̧̧ ve hiç. Kıbrıs Kültürel ve Bilimsel Araştırmalar Enstitüsü.

Jung, C. G. (2019). Dört arketip. Z. A. Y1lmazer (Çev.). İstanbul: Metis.

Kara, R. (1993). Erzincan manileri. Erzincan Sosyal Yardımlaşma ve Dayanışma Vakfı.

Kâşgarlı M. (2013). Divanü Lûgat-it Türk. (Cilt I-II-III). B. Atalay (Çev.). Ankara: TDK.

Kilisli, R. B. (2001). Mâniler. A. Çatıkkaş (Haz.) İstanbul: MEB.

Kurtoğlu, M. (2008). Urfa efsaneleri. İl Kültür ve Turizm Müdürlüğü.

Levend, A. S. (2017). Divan edebiyatı: Kelimeler ve remizler, mazmun ve mefhumlar. (2. bs.). İstanbul: Dergâh.

Malinowski, B. (2016). Bilimsel bir kültür teorisi. D. Uludağ (Çev.). Ankara: Doğubatı. 
Meriç, N. (2019). Toplu öyküleri- II (4.Bask1). İstanbul: YKY.

Ögel, B. (1978). Türk kültür tarihine giriş-3. Ankara: Kültür Bakanlığı.

Özyürek, R. (1991). Mânilerimiz. Ankara: Hacettepe Üniversitesi.

Pakalın, M. Z. (1993). Osmanlı tarih deyimleri ve terimleri sözlüğü (Cilt II). İstanbul: MEB.

Pala, İ. (2015). Ansiklopedik divan şiiri sözlügü. İstanbul: Kap1.

Poe, E. A. (2019). Kuyu ve sarkaç. C.N. Öztürk (Çev.). İstanbul: Karbon.

Roux, J.-P. (1994). Türklerin ve Moğolların eski dini. A. Kazancıgil (Çev.). İstanbul: İşaret.

Sakaoğlu, S. (1983). Kıbrıs Türk masallarl. Ankara: Kültür ve Turizm Bakanlığı.

Şimşek, E. (2001). Yukarıçukurova masallarında motif ve tip araştırması (Cilt II). Ankara: Kültür Bakanlığı.

Thompson, S. (1955-1958). The motif-index of folk-literature (6 cilt). Indiana University.

Türk halk müziği sözlü eserler antolojisi-2 (2000). TRT Müzik Dairesi.

\section{Elektronik kaynaklar}

Balkaya, A. (2014). Halk anlatılarında kuyunun işlevselliği üzerine bir okuma. Milli Folklor, 102, 5364. http://www.millifolklor.com/PdfViewer.aspx?Sayi=102\&Sayfa=50.

Fjellström, P. (1974). The functions of folk costume in Moravian Slovakia by Petr Bogatyrev and Richard G. Crum. Anthropos, S. 69 (3/4), ss. 645-647. https://www.jstor.org/stable/40458599.

Halman, T. S. (1991). Bir kara derin kuyu by Nezihe Meriç: Sarı defter by Handan Saraç: Bu gece Pera'da by Jale Sancak. World Literature Today, S. 65 (1), ss. 183-184. https://www.jstor.org/ stable/40146359.

İnce, A. (2007). “Kuyu cadısı” ve düşündürdükleri. TÜBAR, S. XXI, ss. 109-122. https://dergipark.org. tr/tr/download/article-file/156896.

Karadağ, M. (2017). Ümit İnatçı “Kuyu”da 'hiç'lik ve varoluşu sorguluyor. Lefkoşa Yeni Düzen gazetesi Gaile eki, ss. 407. http://www.yeniduzen.com/umit-inatci-kuyuda-hiclik-ve-varolususorguluyor-86957h.htm

Köktürk, Ş. (2006). Türk destanlarında hapsedilme motifi. TÜBAR S. XIX, ss. 383-400. https:// dergipark.org.tr/tr/download/article-file/156868 .

Turan, M. O. (2013). Kuyu filmindeki arzu kavramının Lacancı psikanalitik yaklaşım çerçevesinde çözümlenmesi. Selçuk Illetişim, S.7 (4), ss. 169-185. https://dergipark.org.tr/tr/download/articlefile/177762

Yıldız, Ö. (2015). Osmanlı hapishaneleri üzerine bir değerlendirme: Karesi Hapishanesi örneği. Gazi Akademik Bakış, 9 (17), 91-111. https://doi.org/10.19060/gab.10180.

Yüksel, A. A. (2016). Metin Erksan'ın Kuyu filminin mitolojiye dayalı bir perspektiften çözümlenmesi. Anadolu Üniversitesi Sosyal Bilimler Dergisi, S. 16 (4), ss. 129-134. https://doi.org/10.18037/ ausbd.415566. 